\title{
POR UMA AGENDA DE PESQUISA COMPARADA DE PAPÉIS PROFISSIONAIS
}

\author{
For a comparative research agenda of professional roles
}

Por una agenda de investigación comparada de papeles profesionales

Danilo Rothberg
Docente do Programa de Pós-Graduação em Comunicação da Faculdade de Arquitetura, Artes
e Comunicação da Unesp (Universidade Estadual Paulista)
danilo.rothberg@ unesp.br $^{-10}$

Kátia Viviane da Silva Vanzini

Mestre e doutora em Comunicação pela Faculdade de Arquitetura, Artes e Comunicação da

Unesp (Universidade Estadual Paulista)

katiavanzini@gmail.com

Pedro Luis Bueno Berti

Mestre e doutorando em Comunicação pela Faculdade de Arquitetura, Artes e Comunicação da Unesp (Universidade Estadual Paulista)

p_berti@hotmail.com

\section{Resumo}

Diversas pesquisas buscam conhecer como jornalistas, estudantes de jornalismo e setores sociais avaliam o papel do jornalismo diante de características históricas, culturais e sociais. Investigações internacionais têm sido desenvolvidas com categorias que permitem comparar aspectos como os papéis que os jornalistas atribuem a si próprios sobre sua missão profissional, ao passo que pesquisas brasileiras contribuem para o diagnóstico de contextos de atuação em função de características culturais singulares, mas podem ser aperfeiçoadas para a detecção de papéis, funções e expectativas. Este artigo apresenta uma revisão da literatura nacional e internacional sobre perfil profissional do jornalista, examinando, sobretudo, os papéis auto-atribuídos. O texto indica similaridades e contrastes entre decisões metodológicas, de modo a apontar desafios e salientar oportunidades e direções de avanço de pesquisa.

Palavras-chave: Jornalismo. Cultura profissional. Papéis profissionais.

\section{Abstract}

Many investigations seek to know how journalists, journalism students and social sectors assess the role of journalism regarding historical, cultural and social characteristics. International research has been developed with categories that allow to compare aspects such as the roles that journalists assign to themselves about their professional mission, while Brazilian research contribute to the diagnosis of contexts of performance related to particular cultural characteristics, but can be improved for the detection of roles, functions and expectations. This article presents a review of the national and international literature on the professional profile of journalists, examining, above all, the self-assigned roles. The text 
indicates similarities and contrasts between methodological decisions, in order to point out challenges and highlight opportunities and directions for the advancement of research.

Keywords: Journalism. Professional culture. Professional roles.

\section{Resumen}

Diversas investigaciones buscan conocer cómo periodistas, estudiantes de periodismo y sectores sociales evalúan el papel del periodismo ante características históricas, culturales y sociales. Las investigaciones internacionales se han desarrollado con categorías que permiten comparar aspectos como los papeles que los periodistas se atribuyen a sí mismos sobre su misión profesional, mientras que las investigaciones brasileñas contribuyen al diagnóstico de contextos de actuación en función de características culturales singulares, pero pueden ser perfeccionadas para la detección de papeles, funciones y expectativas. Este artículo presenta una revisión de la literatura nacional e internacional sobre perfil profesional del periodista, examinando sobre todo los papeles auto-asignados. El texto indica similitudes y contrastes entre decisiones metodológicas, para apuntar desafíos y destacar oportunidades y direcciones de avance de investigación.

Palabras clave: Periodismo. Cultura profesional. Papeles profesionales.

\section{INTRODUÇÃO' ${ }^{1}$}

Diversas pesquisas buscam conhecer como jornalistas, estudantes de jornalismo e setores sociais avaliam normativamente o papel do jornalismo, diante de características históricas, culturais e sociais.

No Brasil, Bergamo, Mick e Lima (2012) coordenaram pesquisa com questionários aplicados a 2.731 jornalistas de todo o país. O estudo apurou aspectos como características demográficas e políticas dos jornalistas e traços gerais da atuação na área, registrando avaliações relevantes sobre temas como autorregulamentação profissional, formação superior obrigatória e satisfação com o trabalho.

O perfil profissional do jornalista brasileiro foi investigado em sua relação com qualidade e deontologia no âmbito de estudos publicados pela Unesco, que verificaram possíveis inter-relações e conformidades da atuação no país diante de princípios normativos propostos pela agência das Nações Unidas a partir de observações empíricas do ambiente internacional de produção de informação (GUERRA, 2010; CHRISTOFOLETTI, 2010; CERQUEIRA, 2010; ROTHBERG, 2010a).

Figaro (2012) investigou o perfil do jornalista atuante no Estado de São Paulo e seus discursos sobre o jornalismo. Os 538 respondentes incluíram 340 jornalistas associados do

\footnotetext{
${ }^{1}$ Uma versão inicial deste artigo foi apresentada no $15^{\circ}$ Encontro Nacional de Pesquisadores em Jornalismo (ECA/USP, São Paulo, 2017). Agradecemos aos participantes pelos comentários que contribuíram ao aperfeiçoamento posterior do texto.
} 
Sindicato dos Jornalistas, 82 de uma empresa editorial e 90 freelancers. As respostas abrangem perfis socioeconômico e de consumo de informação e entretenimento, caraterísticas do trabalho e avaliações sobre desafios profissionais. O estudo possui uma rica dimensão qualitativa obtida em entrevistas que tangenciam os papéis profissionais que os jornalistas atribuem a si próprios, mas as respostas não foram categorizadas de modo a permitir comparações com perfis identificados em pesquisas internacionais.

Investigações internacionais têm sido desenvolvidas com categorias que permitem comparar aspectos como os papéis que os jornalistas atribuem a si próprios sobre sua missão profissional. Um dos estudos de mais abrangência realizado com metodologia desenhada para facilitar comparações internacionais foi realizado pelo Worlds of Journalism Study, consórcio mundial de pesquisadores baseado na Ludwig-Maximilians-Universität München (WJS, 2018). O relatório sobre o Brasil (MOREIRA, 2017) do estudo indica a predominância no país de papéis -atribuídos pelos jornalistas a si próprios - orientados à consecução de ideais éticos como objetividade e distanciamento, idealização que parece contraditória diante de hipóteses apontando o sectarismo das mídias hegemônicas em acontecimentos como a cobertura do impeachment da Presidência da República em 2016 (ALBUQUERQUE, 2017).

Em diversos países, uma parte expressiva das pesquisas que investigam o perfil profissional dos jornalistas busca delimitar certos parâmetros de análise que possam ser eficazes na identificação e classificação dos diferentes papéis por eles desempenhados e auto atribuídos em suas respectivas áreas de competência. Hellmueller et al. (2016) sugerem que a concepção de determinado perfil jornalístico decorre crucialmente da percepção que os jornalistas possuem a respeito da função social específica que sua profissão é suposta de desempenhar diante de características particulares das estruturas políticas nacionais, como divisão de poderes, regras eleitorais, sistemas de pesos e contrapesos etc.

No entanto, Mellado, Hellmueller e Donsbach (2016) advertem a respeito de uma possível lacuna existente entre, de um lado, a concepção idealizada do papel do jornalismo enraizada em culturas nacionais, e do outro, a percepção efetiva que o jornalista possui a respeito de sua atividade, levando em consideração os fatores limitantes do ambiente organizacional, político, econômico e cultural.

Essa lacuna deveria ser preenchida, segundo Mellado, Hellmueller e Donsbach, (2016, p. 35), pelo estudo dos elementos que influenciam e por vezes determinam tanto a concepção quanto a percepção da prática jornalística, de modo que ao se destacar o contexto social no qual o jornalismo está imerso, se torna possível "compreender as estruturas e o sistema no 
qual esses jornalistas trabalham, bem como a maneira com que o poder sobre o conteúdo produzido é negociado dentro dessas mesmas estruturas”.

Diante de tais dificuldades e contradições enfrentadas pela pesquisa comparada em jornalismo, este artigo propõe uma contribuição ao avanço do conhecimento na área. Nosso argumento é baseado em uma revisão original da literatura nacional e internacional de pesquisas sobre perfil profissional do jornalista, que examina, sobretudo, os papéis autoatribuídos. $\mathrm{O}$ texto indica similaridades e contrastes entre as decisões teórico-metodológicas das pesquisas revisadas, de modo a salientar oportunidades e direções de aperfeiçoamento. No percurso aqui adotado, três perfis essenciais são caracterizados, na ordem: entretenimento; intervenção / contribuição política; público / cívico. Os desafios e as contradições são tratados em seção conclusiva que abrange o estado atual dos problemas a serem enfrentados. Considerações finais sintetizam a contribuição do artigo.

\section{DESENVOLVIMENTO}

\subsection{Papéis profissionais: prover entretenimento}

Dalen, Vreese e Albæk (2012) tomam como parte das hipóteses de seu estudo comparado sobre papéis profissionais na Alemanha, Dinamarca, Estados Unidos, Espanha e Reino Unido a consideração de que as instituições políticas formais podem ser cobertas com motivações distintas: de um lado, a área pode ser investigada como fundamental para a vida nacional, merecendo um tratamento sério e vigilante; de outro, a área pode receber atenção moderada, situando-se ao lado de outras editorias em termos de recursos humanos, materiais e financeiros investidos. $\mathrm{E}$ as distintas motivações estariam associadas aos papéis autoatribuídos e teriam efeitos concretos sobre a qualidade da cobertura. A política seria considerada fundamental por aqueles que avaliam sua missão como necessariamente atada a uma contribuição decisiva para o fortalecimento da democracia, e assim as notícias adotariam com frequência enquadramentos temáticos, com contexto e profundidade (ROTHBERG, 2010b). E seria considerada como mais um dos temas possíveis, em igualdade de condições como outras editorias como cultura e esporte, por aqueles que avaliam sua missão como centrada em oferecer um panorama geral e acessível da política ao público, e assim as notícias adotariam com frequência enquadramentos de conflito e jogo, que simplificam as questões em jogo ao reduzi-las a dramatizações e estratégias de ganhos e benefícios. 
Outra hipótese verificada por Dalen, Vreese e Albæk (2012) se relaciona ao papel autoatribuído pelos jornalistas que oscila entre, de um lado, atuar como disseminador de notícias que auxiliem o público a tomar decisões informadas necessárias à afirmação democrática, e de outro lado fornecer distração e entretenimento como forma de refúgio do cotidiano para o público, com notícias adotando narrativas atraentes para facilitar o relaxamento, focando sobretudo em escândalos e vida íntima dos políticos.

O desenho de pesquisa de Dalen, Vreese e Albæk (2012) incluiu análise de conteúdo de notícias, com o objetivo de verificar possíveis impactos de perfis profissionais, e aplicação de questionários a 425 jornalistas.

A Espanha se destacou no aspecto de cobertura séria da política, com mais jornalistas atribuindo a si mesmos a responsabilidade por manter a qualidade do debate democrático, e matérias com menos enquadramentos de conflito e jogo entre os cinco países estudados. $\mathrm{O}$ Reino Unido se destaca como país onde predomina a função de notícias orientadas ao entretenimento, com mais jornalistas atribuindo tal papel a si próprios e mais extensa cobertura de escândalos baseados na exposição da vida íntima de políticos.

Coleman et al. (2016) verificaram a disposição de 678 estudantes de jornalismo nos Estados Unidos para adotar preferencialmente um entre quatro papéis profissionais usualmente presentes nas sondagens do gênero, a saber: 1. Disseminação (consiste em oferecer com velocidade informações ao público, fornecer entretenimento e relaxamento e dar preferência a notícias que interessem a uma audiência o mais ampla possível); 2. Interpretação / investigação (analisar e interpretar problemas complexos, investigar alegações e declarações oficiais); 3. Mobilização (atender interesses intelectuais e culturais do público, agendar o debate público, dar às pessoas comuns a oportunidade de expressão de suas visões e motiválas ao envolvimento com a vida cívica, apontando possíveis soluções para os problemas da vida democrática); 4. Adversarial (adversário e fiscalizador persistente de funcionários públicos e empresas privadas).

As perguntas do questionário aplicado por Coleman et al. (2016) se relacionaram indiretamente a estes quatro papéis, buscando registrar as motivações implícitas à escolha da faculdade. O papel de interpretação / investigação esteve à frente entre a amostra sondada, coincidindo com resultados trazidos por outros estudos da população profissional. Os estudantes diferem dos profissionais em relação ao segundo papel mais citado como desejável e necessário: enquanto os profissionais indicam o papel adversarial como o segundo mais importante, os estudantes indicam o papel de disseminação, logo abaixo do papel de 
interpretação / investigação, como preferido, em função de sua atração por notícias leves (soft news), orientadas ao entretenimento.

Este aspecto foi aprofundado em grupos focais conduzidos por Coleman et al. (2016). "Dos grupos focais, a importância de entretenimento e notícias sobre estilos de vida surgiram como tão importantes quanto as tradicionais notícias 'difíceis' da política, do crime e da economia", segundo Coleman et al. (2016, p. 14): "muitos mencionaram que o jornalismo estava se afastando das notícias difíceis e movimentando-se em direção ao entretenimento, e poucos lamentavam esse fato". Na verdade, muitos defenderam o que então viam como uma tendência inexorável: "matérias sobre novas tecnologias, (...) música, filmes e 'notícias que você poderia usar' eram tão importantes quanto matérias sobre crimes, assassinatos e incêndios"; o tradicional conceito de jornalismo estava "desatualizado" para eles (COLEMAN et al., 2016, p. 14).

Tal predileção por notícias com menor compromisso com o fortalecimento da democracia foi, justamente, detectada por estudos de papéis profissionais entre estudantes chineses, conforme Yang e Arant (2014). Vivendo em um país não democrático, em que a ausência de liberdade de imprensa restringe decisivamente a possibilidade de exercício de papéis de interpretação e investigação, os estudantes chineses declararam preferência pelo desenvolvimento de uma carreira profissional de forma independente da possível contribuição para a vida política: "os estudantes chineses estão mais focados em satisfazer suas necessidades individuais e desenvolver suas habilidades próprias porque entendem a função limitada dos meios de comunicação chineses sob controle estrito do governo" (YANG; ARANT, 2014, p. 36).

Os estudantes de jornalismo chineses declararam achar mais difícil driblar o conflito de interesses e realizar uma representação justa do que os americanos. "Os estudantes americanos atribuíram maior importância à investigação ações de governo e à discussão de políticas públicas nacionais" em relação aos estudantes chineses (YANG; ARANT, 2014, p. $45)$.

Os americanos relataram a importância do papel contestador e vigilante das ações públicas, o que poderia justificado por haver liberdade de imprensa em seu país. No entanto, “embora a educação jornalística possa melhorar as habilidades e técnicas dos alunos, é o contexto maior dos ambientes políticos e sociais que determina o que pode ser feito pelos meios de comunicação" (YANG; ARANT, 2014, p. 45). 
Em marcado contraste com o papel de entretenimento, se coloca o papel de intervenção e contribuição política, caracterizado na próxima seção.

\subsection{Papéis profissionais: intervenção e contribuição política}

Um número crescente de estudos tem verificado a existência de um modelo de perfil profissional denominado intervencionista, que idealmente atuaria na realidade política de uma sociedade supostamente alterando o rumo dos acontecimentos sociais ao dar publicidade a informações provenientes de investigações, acesso a documentos restritos, checagem de dados sigilosos e fontes alternativas de investigação (ALBUQUERQUE, 2005; HANITZSCH, 2016; MELLADO \& VAN DALEN, 2017; EL ISSAWI \& CAMMAERTS, 2016).

Esse papel apresenta duas vertentes distintas de atuação na esfera jornalística: um primeiro, de watchdog, que centraliza as suas atividades em torno das ações dos governantes no poder e do processo político de maneira geral; e um segundo, que apura as informações de uma maneira mais ágil, com pouca ênfase investigativa, sobre acontecimentos cotidianos da sociedade.

De acordo com Hellmueller et al. (2016), um dos perfis mais conhecidos e bem estabelecidos no conjunto dos papéis jornalísticos é o de watchdog. Acredita-se que esse modelo de perfil profissional tenha surgido conceitualmente nos Estados Unidos na década de 1960, com o advento da Guerra do Vietnã, movimentos por direitos civis e escândalos de corrupção, que deram visibilidade à função do jornalista como um investigador das ações do governo, sempre atento ao processo político e as suas relações com a esfera econômica da sociedade.

Procedendo a uma investigação quantitativa e de análise de conteúdo, Hellmueller et al. (2016) reuniram um total de 1.421 notícias e artigos publicados em cinco grandes jornais dos Estados Unidos (The New York Times, The Washington Post, The Los Angeles Times, USA Today, e Wall Street Journal) classificando-os em torno de dez itens que caracterizavam a informação como proveniente de um trabalho de fiscalização do poder público (watchdog): informação sobre processo administrativo ou judicial, avaliação do jornalista, avaliação da fonte, crítica do jornalista, crítica da fonte, denúncia do jornalista, denúncia da fonte, conflito ou confrontação, investigação externa e relatórios investigativos. Os resultados indicaram que o modelo watchdog esteve presente predominantemente em histórias que tratavam de religião, governo, polícia e crime. 
Willnat e Weaver (2014) observaram um aumento do papel de watchdog entre os anos de 1971 e 2013, por meio de cinco pesquisas conduzidas durante o período. A primeira, de 1971, apontou que 76\% dos entrevistados viam-se representantes dessa função, 66\% em 1982, 66,7\% em 1992, 70,5\% em 2002, e 78,2\% em 2013.

Hanitzsch e Vos (2016), baseados em uma extensiva revisão da literatura, detectaram a presença de três papéis jornalísticos mais recorrentes, entre 18 mais citados, sendo aquele que se enquadra na função intervencionista, denominado "crítico-monitorador", encontrado predominantemente em países ocidentais. Esse pode ser caracterizado como representante do ideal que coloca a mídia como o quarto poder de uma sociedade, com jornalistas que exercem uma posição crítica em relação aos outros poderes e que percebem a imprensa como uma peça importante no sistema de freios e contrapesos de um regime democrático. Segundo Hanitzsch e Vos (2016, p. 9), os jornalistas que cumprem o papel de watchdogs, de forma idealizada, "ativamente escrutinam as decisões de líderes políticos e econômicos e fornecem uma crítica independente à sociedade e suas instituições”.

Segundo Abdenour e Riffe (2016), o papel investigativo e fiscalizador do poder público foi o perfil profissional mais citado $(58,8 \%)$ entre 165 jornalistas entrevistados que atuavam no setor de telecomunicação dos Estados Unidos (NBC, ABC, CBS e Fox). Todavia, o resultado apresentou algumas nuances: desse total de jornalistas, numa escala de 1 a 5 , que variava do "descordo totalmente" ao "concordo totalmente", a maioria (4.52 na escala) concordou que a sua função era reportar as notícias de maneira rápida ao público, contrastando com o tempo necessário para o processamento de uma reportagem investigativa, que pode levar de semanas a meses; em seguida (4.42 na escala), os jornalistas consideraram que a função principal do profissional investigativo é checar os dados e ações do governo, enquanto que os demais (4.41 na escala) avaliou que análise de problemas complexos era a principal responsabilidade da investigação jornalística.

No entanto, como indicam El Issawi e Cammaerts (2016), o ambiente de liberdade de imprensa em que as empresas jornalísticas trabalham acaba determinando o tipo específico de papel desempenhado pelos jornalistas na sociedade. Nesse sentido, a liberdade de imprensa é uma pré-condição importante para a existência do papel de watchdog nas atividades jornalísticas.

Adotando o método de entrevistas, de questionário semiaberto, com 50 jornalistas, os autores detectaram que os profissionais egípcios viam o perfil de watchdog dependente "da 
libertação dos ditames do discurso oficial bem como da interferência dos proprietários de mídia” (EL ISSAWI; CAMMAERTS, 2016, p. 562).

No entanto, na prática, os jornalistas indicavam que a ausência de uma tradição investigativa, pouca técnica profissional e um legado de dependência dos governos militares que controlavam os órgãos de imprensa eram fatores que limitavam a prática de um jornalismo voltado para a fiscalização das políticas e ações governamentais. Segundo El Issawi e Cammaerts (2016, p. 562), o Egito durante os governos de Mubarak e da Irmandade Muçulmana impôs o "controle militar e estatal sobre a mídia através de uma estrutura regulatória opressiva que impunha restrições sobre os noticiários independentes".

No mesmo sentido, analisando o perfil dos jornalistas chilenos, Mellado e Van Dalen (2017) apontam a transformação pela qual passou a estrutura política da sociedade, partindo de um ambiente de censura ditatorial para a retomada da liberdade de imprensa durante o período de redemocratização, como um dos elementos condicionantes para a percepção do jornalista a respeito de sua função social. De modo a sugerir a confirmação da associação positiva entre democracia, liberdade de imprensa e o papel do jornalista como watchdog, os autores verificaram, por meio de análise de conteúdo aplicada em mais de 20 mil artigos, uma tendência de crescimento do papel do jornalista como um fiscalizador do poder público, tomando o partido do cidadão comum contra a elite política e econômica, principalmente entre os anos de 1990 e 2011.

No Brasil, a predileção por características profissionais como objetividade e distanciamento corrobora a predominância de traços de atuação sintonizada ao perfil watchdog, embora no país a menor ênfase em provisão de "informações que as pessoas precisam para tomar decisões políticas" em comparação com a exigência de "reportar os fatos como eles são" sugere contradições difíceis de serem explicadas (MOREIRA, 2017).

O papel de intervenção e contribuição política pode se desenvolver em uma direção específica, na qual o engajamento do jornalista se materializa em ações de envolvimento do público na formação de pautas e agendas de cobertura, conhecidas como jornalismo público, cívico ou comunitário. Este é o foco da próxima seção.

\subsection{Papéis profissionais: público ou cívico}

Herscovitz (2004) avaliou diversos aspectos que interferem na maneira como os jornalistas brasileiros avaliam o papel do jornalismo, buscando identificar aspectos como a 
possível influência de modelos herdados do jornalismo estadunidense e europeu e a preponderância de matrizes éticas, dimensões culturais e sociopolíticas. Profissionais entrevistados na cidade de São Paulo afirmaram que investigar ações do governo, exercendo vigilância sobre o bem público, é um dos papéis mais importantes da mídia $(65,7 \%$ assim indicaram) seguido pelo repasse de informações ao público $(63,7 \%)$. Ou seja, os papéis de investigação e disseminação figuram como os mais importantes. No entanto, a maioria (60\%) afirma desconhecer o código de ética profissional, ao passo que 30\% conhecem e aplicam, e $10 \%$ conhecem, mas não aplicam.

Trabalhos têm indicado que o uso das tecnologias de informação e comunicação nas redações interfere na concepção do papel que os jornalistas atribuem a seu trabalho, principalmente a partir da perspectiva de que as novas mídias têm significado novos desafios e oportunidades para os negócios baseados na produção e distribuição de notícias, para as ferramentas e técnicas utilizadas e as habilidades requeridas (WEISS, 2015). Entre os principais impactos apontados pelos jornalistas investigados, está a necessidade de o jornalista e as estruturas de redação estarem abertos à opinião pública e ao diálogo. Jornalistas brasileiros, argentinos e mexicanos afirmaram que as tecnologias têm sido úteis para a coleta de notícias, pesquisa e checagem dos fatos. Os jornalistas sondados afirmaram que usam redes sociais na rotina de trabalho para postar informações $(34,5 \%)$, comunicar-se com o público $(22,9 \%)$, procurar informações $(34,5 \%)$, pesquisar $(16,6 \%)$ e encontrar fontes $(5 \%)$.

O papel interpretativo é o mais citado entre os jornalistas de cinco países investigados, incluindo os brasileiros. "Os papéis de mobilizadores, disseminadores e intérpretes foram os mais associados nas tarefas diárias de mídias sociais (...). A rotina de usar a mídia digital e as mídias sociais no trabalho de notícias diárias pode ser incorporada ao papel de mobilizador e intérprete" (WEISS, 2015, p. 95).

Tandoc Jr (2014) investigou entre estudantes de jornalismo como os padrões de consumo das notícias têm influenciado a maneira como os jornalistas realizam seu trabalho, modificando também o papel que os jornalistas exercem em uma sociedade. Os estudantes de jornalismo afirmaram que o papel de intérprete das notícias é o mais importante, seguido pelos papéis de disseminador de notícias; entretenimento; adversário; de mobilização. $\mathrm{O}$ impacto do uso das redes sociais também deve ser considerado na pesquisa, porque além de ser uma nova fonte de informação, destaca-se pela rapidez com que consegue atingir grandes audiências. Tal fator explicaria porque os entrevistados também consideram como papel do jornalismo a disseminação rápida de informações. O autor recomenda que as faculdades de 
jornalismo deveriam incentivar que os estudantes avaliassem novos papéis para o jornalismo, como dar voz a quem usualmente não conseguiria obter espaços de reivindicação, o que se associaria com o papel cívico.

Traquina (2015) indica a cobertura da campanha presidencial nos Estados Unidos em 1988 como marco no desenvolvimento do jornalismo cívico naquele país. Naquele momento, caracterizado por declínio em circulação e audiência dos jornais, agravou-se o questionamento da credibilidade da imprensa. Uma resposta da indústria de notícias foi o crescimento do jornalismo cívico, fato percebido, entre outras iniciativas, quando um jornal "abandonou o seu papel tradicional de observador desligado e assumiu um papel de ativista na tentativa de melhorar a qualidade de vida na comunidade", ao encomendar uma "sondagem para identificar os problemas que preocupavam a comunidade" (TRAQUINA, 2015, p. 295). As iniciativas que originaram o jornalismo cívico surgem em uma época em que os jornais procuraram aproximar suas ações das comunidades onde estavam inseridos, visando reverter a queda do número de leitores. Para Fernandes (2007), o papel de advocate (defensor) é o que mais caracteriza o jornalismo cívico, também denominado público, comunitário e cidadão.

Outras propostas que se multiplicaram em diversas cidades norte-americanas procuraram "dar centralidade ao cidadão e a seus anseios e necessidades, reafirmando a democracia e incentivando a participação política da população" (LIMA; MOTA, 2014, p. 651). Os seguidores de tal proposta acreditam que o jornalista deve ir além de disseminar a notícia. Ele deve: preocupar-se com os efeitos da notícia produzida para a melhoria da vida pública; exercer um papel mais participativo com o que acontece em sua comunidade; e passar a ver o público como agente ativo de mudanças em aspectos de seu interesse. "Assim, para o jornalismo cívico, torna-se um imperativo que o jornalismo encoraje o envolvimento do cidadão na vida pública, desenvolvendo nos jornalistas uma nova perspectiva - a perspectiva do "participante justo"” (TRAQUINA, 2015, p. 299).

“Os jornalistas públicos partem da premissa de que é necessário reanimar o debate público, pois a informação por si só não é suficiente. É necessário interpelar o cidadão para que ele participe" (COSTA FILHO, 2006, p. 127). Um dos desafios do jornalismo público é criar e manter oportunidades de participação do público na formulação de pautas em redações (ROTHBERG, 2011).

Traquina (2015) comenta que apesar das iniciativas de jornalismo cívico parecerem mais conectadas com a cidadania, elas sofreram diversas críticas, entre elas a de que seriam utilizadas como estratégia de marketing para ampliar audiência e circulação. "O movimento 
provocou uma discussão dentro do jornalismo norte-americano sobre os valores fundamentais para a profissão e lançou uma alerta que preconiza uma quebra com rotinas gastas e asfixiantes. Mas o futuro do jornalismo cívico depende, em certa medida, se o movimento pressagia uma reforma ou uma revolução" (TRAQUINA, 2015, p. 304)

Mellado et al. (2016) investigaram como os jornalistas de cinco países da América Latina avaliam o papel da profissão, sendo que o jornalismo cívico é citado por jornalistas mexicanos e equatorianos, seguidos pelos cubanos, chilenos e brasileiros. Para os autores, tais resultados podem ser justificados por questões culturais, sociais e políticas de cada realidade, principalmente no que diz respeito às relações estabelecidas entre jornalistas e detentores de cargos públicos.

Entre as pesquisas que buscam investigar como o cidadão avalia os papéis do jornalismo, Nah e Chung (2011) procuram verificar o papel cada vez mais presente do jornalismo cívico, diante do crescimento do número de cidadãos que colaboraram por meio da produção de conteúdos em diversos formatos para o jornalismo, principalmente no telejornalismo. Segundo os autores, as próprias organizações estão aprendendo com tais práticas para aumentar o engajamento em suas atividades, o que se reflete também na percepção dos cidadãos comuns, que acabam encontrando formas de envolvimento por meio de websites e redes sociais.

Os espaços digitais incentivariam a criação de oportunidades de diálogo com o público, uma das premissas do jornalismo cívico. Para Nah e Chung (2011, p. 715), tais práticas podem desenvolver esferas públicas virtuais, "facilitando discussões democráticas saudáveis", além de potencialmente criarem capital social por meio de estabelecimento de laços de confiança em redes sociais que proporcionam a interação entre jornalistas e cidadãos: "o capital social - como confiança e credibilidade da mídia - pode influenciar a inter-relação entre jornalistas profissionais, jornalistas cidadãos e público alvo das notícias".

Nah e Chung (2011) investigaram cinco papéis atribuídos ao exercício do jornalismo: disseminador, intérprete, adversário, mobilizador e cívico. Neste caso, o papel cívico incluiu ações como realizar pesquisas para saber quais são as questões consideradas prioritárias entre os cidadãos; organizar reuniões entre cidadãos e líderes comunitários para debater assuntos públicos; motivar os cidadãos para que façam parte de tomadas de decisões sobre assuntos de interesse público; tentar incluir cidadãos comuns como fontes das matérias que envolvem debates públicos. Conforme um dos resultados da pesquisa, leitores de edições online percebem a importância do trabalho não apenas dos jornalistas profissionais, mas também dos 
jornalistas cidadãos na comunidade onde vivem. Mas, em avaliação geral dos resultados, os autores indicaram que "independentemente do tipo de jornalista, os jornalistas profissionais e os cidadãos devem ser críticos e vigilantes sobre as ações públicas, elites políticas e empresariais" (NAH; CHUNG, 2011, p. 726).

\subsection{Conclusões: desafios das pesquisas de papéis profissionais}

Cabe, finalmente, retomar aspectos da literatura aqui revisada e adicionar, ao nosso argumento, referências que nos permitem fazer um balanço conclusivo dos desafios postos às pesquisas de papéis profissionais.

Complicações teórico-metodológicas foram detalhadas por Mick (2017) e Mick e Schmitz (2017), que indicam aspectos decorrentes da dificuldade de formulação de questionários padronizados o suficiente para permitir sua aplicação em culturas bastante distintas entre si. Questões interessadas em captar expectativas sobre papéis profissionais podem ser interpretadas por idealizações sobre a própria atuação que se encontram profundamente marcadas por configurações políticas, conjunções históricas e até mesmo acontecimentos ocorridos meses anteriores à realização da sondagem, problema antes apontado por Albuquerque (2012a).

O senso de dever cívico, por exemplo, que caracteriza o papel segundo o qual é função dos jornalistas favorecer o empoderamento democrático de seus públicos, pode variar enormemente entre os diversos países. Pode implicar tanto considerações abstratas sobre o que deve ser o exercício de voto consciente, que dispensaria o envolvimento ativo em movimentos sociais, quanto crenças sobre a urgência de estabelecer uma democracia participativa, passando por diferentes graus de inserção social e política. O papel de intervenção/contribuição política, por sua vez, é sensível a influências que levam a uma rigorosa seletividade dos alvos contra os quais os jornalistas dirigem seu trabalho de apuração. Tais influências podem ser de ordem cultural, como crenças não assumidas sobre quais partidos são mais provavelmente corruptíveis ou não, ou ligadas às práticas de poder nas redações, como imposição de determinados alvos pelo comando editorial, com a correspondente exclusão ou tratamento amenizado de outros alvos. Uma saída metodológica para contornar este risco é a adoção de metodologia semelhante como aquela empregada por Mellado e Van Dalen (2017), que determinou uma amostra de análise da cobertura jornalística incluindo notícias publicadas por dois grandes jornais com orientações políticas distintas em 
um período de onze anos. A seleção com um amplo recorte temporal tenderia a evitar a possibilidade de que um único governo de ocasião fosse situado como adversário contra o qual os jornalistas direcionam suas críticas, o que contaminaria a autopercepção de seu próprio papel profissional com predisposições determinadas.

Neste ponto, é possível sustentar que a pesquisa comparada em jornalismo requer articulações lógicas de construção e aplicação de tipos ideais que, em contextos anteriores, já se mostraram extremamente controversas. É o caso dos modelos que conduziram às teses de paralelismo político entre sistemas de mídia e sistemas político (HALLIN; MANCINI, 2004), que posteriormente se mostraram de validade restrita a outras partes do globo (ALBUQUERQUE, 2012b; RANTANEN, 2013). Os questionários de papéis profissionais têm outra tessitura, de fato, mas também envolvem construção de tipos ideais igualmente discutíveis.

Além disso, na aplicação de questionários de uma pesquisa comparada internacional no Brasil, Mick e Schmitz (2017) relatam obstáculos já vivenciados por outras investigações em parte similares (GUERRA, 2010; CHRISTOFOLETTI, 2010; CERQUEIRA, 2010; ROTHBERG, 2010a), relacionados à resistência dos jornalistas em cooperar com os pesquisadores, em função de um traço que, embora não exclusivo ao Brasil, parece mais forte no país, de indiferença e animosidade em relação à academia. Estudos etnográficos de newsmaking como aqueles empreendidos por Chaparro (1994) e Travancas (1993) parecem confinados a um passado distante, no qual a permanência de um observador supostamente neutro nas redações por períodos prolongados de observação e análise era factível. No cenário atual de demissões, redução de quadros nas redações e pressões de toda ordem, as tentativas dos pesquisadores de obter respostas dos jornalistas tendem a ser ignoradas, mesmo quando os estudos são devidamente apresentados com o lastro de instituições de credibilidade.

O desafio de receber a atenção dos públicos a serem sondados têm sido enfrentado de formas variadas. Nah e Chung (2011) buscaram viabilizar a participação de leitores em sua pesquisa por meio de parceria com os editores dos veículos investigados, que publicaram em suas páginas web informações sobre o teor da pesquisa. Já Herscovitz (2004) buscou incrementar a participação dos profissionais por meio de contatos pessoais e profissionais. Yang e Arant (2014) contaram com professores de graduação para facilitar o engajamento de estudantes. Tandoc Jr. (2014) utilizou, como estímulo à participação de estudantes de jornalismo, a oferta de créditos para cursar disciplinas. Mas isto levou à segmentação indesejada da amostra, já que estudantes do primeiro ano de graduação acabaram se tornando 
predominantes entre os entrevistados. Tandoc Jr. (2014) avaliou esta tendência como uma limitação importante de sua pesquisa, ao considerar que a concepção do papel do jornalista poderia ser modificada nos estágios finais da formação universitária.

Apesar de amplamente embasadas e das escolhas metodológicas, os autores também puderam indicar algumas limitações dos métodos utilizados. Para Nah e Chung (2011), uma das lacunas apontadas foi a ausência da investigação sobre papéis jornalísticos emergentes resultantes das tecnologias de informação e comunicação. Os autores também consideraram a necessidade de uma pesquisa por amostragem representativa, que poderia oferecer um conjunto demográfico mais diversificado. Para Herscovitz (2014), as pesquisas na área deveriam considerar as peculiaridades da prática profissional do jornalismo em países em desenvolvimento, pois "a mera replicação de instrumentos de pesquisa em estudos transnacionais enfrenta restrições culturais e técnicas que impedem generalizações" (HERSCOVITZ, 2004, p. 85). Ou seja, a sistematização das variáveis dos sistemas de mídia a serem consideradas pelos questionários de pesquisa devem estar atentas a práticas para além das democracias ocidentais (STEIN, 2013; MELLADO et al, 2016; EL ISSAWI; CAMMAERTS, 2016).

Por fim, questionários podem não ser suficientes. Yang e Arant (2014) recomendam a utilização complementar de entrevistas semiestruturadas e grupos focais.

Em síntese, podemos indicar três direções essenciais para os aperfeiçoamentos metodológicos na pesquisa comparada de papéis profissionais, detectáveis no conjunto da literatura especializada aqui revisada: a adoção de estratégias para obter a participação na pesquisa do público a ser sondado é imprescindível, incluindo o dimensionamento de estímulos adequados; a determinação de tipos ideais de atuação profissional, em relação aos quais se busca conhecer os perfis existentes, deve ir além dos padrões correntes nas democracias ocidentais; e a formulação de questionários deve ser flexível o suficiente para permitir a captação de traços diversos de culturas distintas, tarefa que pode ser aprimorada pela aplicação de métodos adicionais de pesquisa qualitativa.

\section{CONSIDERAÇÕES}

Este artigo se dedicou à revisão da literatura recente sobre as pesquisas científicas que buscam identificar papéis profissionais auto-atribuídos por jornalistas e estudantes da área para o desenvolvimento de sua atuação. $\mathrm{O}$ objetivo do trabalho foi indicar parâmetros para as 
decisões metodológicas de futuras pesquisas similares no Brasil, que têm avançado em direções importantes e podem se beneficiar da diversidade de realizações de pesquisa em diversos países.

As decisões metodológicas na pesquisa em comunicação estão relacionadas a opções com implicações operacionais que estão lastreadas em determinados recortes de apropriação da literatura científica (BRAGA, 2011). Neste sentido, o percurso adotado por este artigo, em função das limitações de espaço, concentrou-se em apresentar uma abordagem das características gerais de papéis profissionais usualmente presentes em investigações comparativas internacionais.

Entre os diversos papéis profissionais apurados pelas pesquisas, três mereceram atenção preponderante aqui: entretenimento, intervenção/contribuição política e público/cívico. As variações entre eles assumem antecedentes em relação a expectativas de atuação e efeitos sobre o conteúdo da cobertura jornalística. Embora envolvam inevitavelmente certa idealização para tornar visíveis seus traços típicos, os papéis permanecem como válidos para o avanço do conhecimento na área, mas sua aplicação empírica não pode ignorar ressalvas importantes, que requerem a problematização rigorosa do objeto de análise.

Sobretudo, é necessário demonstrar se os traços de cada um dos três papéis profissionais, conforme aqui delineamos, são suficientemente objetivos para sua tradução em perguntas sintéticas de questionários que possam, além de registrar singularidades nacionais, permitir comparações com o cenário internacional. As pesquisas realizadas nos programas de pós-graduação em comunicação e jornalismo no Brasil terão muito a se beneficiar se puderem avançar de modo a ampliar seu lastro científico e fortalecer suas decisões metodológicas.

\section{Agradecimentos}

Pedro Luis Bueno Berti e Kátia Viviane da Silva Vanzini agradecem à Fundação de Amparo à Pesquisa do Estado de São Paulo (FAPESP) pelas bolsas, respectivamente, de Mestrado (Processo 2015/23669-9) e Doutorado (Processo 2016/09134-8).

\section{REFERÊNCIAS}

ABDENOUR, Jesse; RIFFE, Daniel. The investigative DNA: role conceptions of local television investigative journalists. Electronic News, v. 10, n. 4, p. 224-242, 2016.

ALBUQUERQUE, Afonso de. Another 'Fourth Branch' Press and political culture in Brazil. Journalism, v. 6, n. 4, p. 486-504, 2005. 
$2012 \mathrm{a}$.

. O paralelismo político em questão. Revista Compolítica, v. 2, n. 1, p. 5-28,

. On models and margins: comparative media models viewed from a

Brazilian perspective. In: HALLIN, D. C.; MANCINI, P. (eds.). Comparing media systems beyond the western world. Cambridge: Cambridge University Press, 2012b.

Protecting democracy or conspiring against it? Media and politics in Latin

America: A glimpse from Brazil. Journalism, p. 1-18, 2017.

BERGAMO, Alexandre; MICK, Jacques; LIMA, Samuel. Perfil do jornalista brasileiro. Características demográficas, políticas e do trabalho: síntese dos principais resultados. Florianópolis: UFSC, Fenaj, 2012.

BRAGA, José Luiz. A prática da pesquisa em Comunicação: abordagem metodológica como tomada de decisões. E-Compós, v. 14, n. 1, p. 1-33, 2011.

CERQUEIRA, Luiz Augusto Egypto. Qualidade jornalística: ensaio para uma matriz de indicadores. Série Debates CI Unesco, n. 6, 2010.

CHAPARRO, Manuel Carlos. Pragmática do jornalismo. São Paulo: Summus, 1994.

CHRISTOFOLETTI, Rogério. Indicadores da qualidade no jornalismo: políticas, padrões e preocupações de jornais e revistas brasileiros. Série Debates CI Unesco, n. 3, 2010.

COLEMAN, Renita et al. Why be a journalist? US students' motivations and role conceptions in the new age of journalism. Journalism, p. 1-20, 2016.

COSTA FILHO, Paulo Celestino. Jornalismo público: por uma nova relação com os públicos. Organicom, v. 3, n. 4, p. 124-141, 2006.

DALEN, Arjen Van; VREESE, Claes Holger de; ALBÆK, Erik. Different roles, different content? A fourcountry comparison of the role conceptions and reporting style of political journalists. Journalism, v. 13, n. 7, p. 903-922, 2012.

EL ISSAWI, Fátima; CAMMAERTS, Bart. Shifting journalistic roles in democratic transitions: Lessons from Egypt. Journalism, v. 17, n. 5, p. 549-566, 2016.

FERNANDES, Márcio Ronaldo Santos. Civic journalism no Brasil: a construção de um plano de referência para um jornalismo público. In: MARTINS, M. L.; PINTO, M. Comunicação e Cidadania. Actas do $5^{\circ}$ Congresso da Associação Portuguesa de Ciências da Comunicação. Braga, 2007.

FIGARO, Roseli. O perfil do jornalista e os discursos sobre o jornalismo: um estudo das mudanças no mundo do trabalho do jornalista profissional em São Paulo. Relatório Final da Pesquisa. São Paulo: ECA/USP, 2012.

GUERRA, Josenildo Luiz. Sistema de gestão da qualidade aplicado ao jornalismo: uma abordagem inicial. Série Debates CI Unesco, n. 5, 2010.

HALLIN, Daniel C.; MANCINI, Paolo. Comparing media systems: three models of media and politics. Cambridge: Cambridge University Press, 2004. 
HANITZSCH, Thomas; VOS, Tim P. Journalism beyond democracy: A new look into journalistic roles in political and everyday life. Journalism, p. 1-19, 2016.

HELLMUELLER, Lea et al. The contextualization of the watchdog and civic journalistic roles: Reevaluating journalistic role performance in US newspapers. Palabra Clave, v. 19, n. 4, p. 1072-1100, 2016.

HERSCOVITZ, Heloiza Golbspan. Brazilian journalists' perceptions of media roles, ethics and foreign influences on Brazilian journalism. Journalism Studies, v. 5, n. 1, p. 71-86, 2004.

LIMA, Marcus Antônio Assis; MOTA, Flávia. Moreira Mota. Análise cívica do jornalismo: categorias para a avaliação de produtos jornalísticos. Contemporânea: Comunicação e Cultura. v. 12, n. 3, p. 650667, 2014.

MELLADO, Cláudia et al. Journalistic performance in Latin America: A comparative study of professional roles in news content. Journalism, p. 1-20, 2016.

MELLADO, Claudia; HELLMUELLER, Lea; DONSBACH, Wolfgang. (Eds.). Journalistic role performance: concepts, contexts, and methods. Taylor \& Francis, 2016.

MELLADO, Claudia; VAN DALEN, Arjen. Changing times, changing journalism: a content analysis of journalistic role performances in a transitional democracy. The International Journal of Press/Politics, v. 22, n. 2, p. 244-263, 2017.

MICK, Jacques. Trabalho jornalístico e mundialização: problemas teórico-metodológicos. Sur le journalisme, About journalism, Sobre jornalismo, v. 6, n. 2, p. 68-81, 2017.

MICK, Jacques; SCHMITZ, Aldo. Pesquisa comparativa internacional em jornalismo: desafios teóricometodológicos. Estudos em Jornalismo e Mídia, v. 14, n. 2, p. 62-74, 2017.

NAH, Seungahn; CHUNG, Deborah S. When citizens meet both professional and citizen journalists: Social trust, media credibility, and perceived journalistic roles among online community news readers.

Journalism, v. 13, n. 6, p. 714-730, 2011.

RANTANEN, Terhi. A critique of the systems approaches in comparative media research: a Central and Eastern European perspective. Global Media and Communication, v. 9, n. 3, p. 257-277, 2013.

ROTHBERG, Danilo. Jornalistas e suas visões sobre qualidade: teoria e pesquisa no contexto dos "Indicadores de Desenvolvimento da Mídia" da Unesco. Série Debates CI Unesco, n. 4, 2010a.

O conceito de enquadramento e sua contribuição à crítica de mídia. In:

CHRISTOFOLETTI, R. (org.). Vitrine e vidraça: crítica de mídia e qualidade no jornalismo. Covilhã: Labcom Books; Universidade da Beira Interior, 2010b. p. 53-68.

Jornalismo público: informação, cidadania e televisão. São Paulo: Unesp, 2011.

STEIN, Elizabeth Ann. The unraveling of support for authoritarianism: The dynamic relationship of media, elites, and public opinion in Brazil, 1972-82. The International Journal of Press/Politics, v. 18, n. 1, p. 85-107, 2013.

TANDOC JR., Edson.C. The roles of the game: the influence of news consumption patterns on the role conceptions of journalism students. Journalism \& Mass Communication Educator, v. 69, n. 3, p. 256270, 2014. 
TRAQUINA, Nelson. Jornalismo cívico. In: PEIXINHO, A.T.; CAMPONEZ, C.; VARGUES, I.; FIGUEIRA, J. (orgs.)e 20 anos de jornalismo contra a indiferença. Universidade de Coimbra, 2015. p. 293-306.

TRAVANCAS, Isabel Siqueira. O mundo dos jornalistas. São Paulo: Summus, 1993.

WEISS, Amy Schmitz. The digital and social media journalist: A comparative analysis of journalists in Argentina, Brazil, Colombia, Mexico, and Peru. The International Communication Gazette, v. 77, n. 1, p. 74-101, 2015.

WILLNAT, Lars; WEAVER, David H. The American journalist in the digital age: How journalists and the public think about U.S. journalism. AEJMC, Montreal, 2014.

WJS. WORLDS OF JOURNALISM STUDY. Welcome. Disponível em: http://www.worldsofjournalism.org/. Acesso em: 2 fev. 2018.

YANG, Jin; ARANT, David. The roles and ethics of journalism: how Chinese students and American students perceive them similarly and differently. Journalism \& Mass Communication Educator, v. 69, n. 1, p. 33-48, 2014.

Original recebido em: 07 de fevereiro de 2018

Aceito para publicação em: 12 de agosto de 2018

\section{Danilo Rothberg}

Livre-docente em Sociologia da Comunicação. Bacharel em Comunicação, Mestre em Comunicação e Doutor em Sociologia pela Unesp (Universidade Estadual Paulista). Docente do

Departamento de Ciências Humanas da Faculdade de Arquitetura, Artes e Comunicação (Faac) da Unesp. Coordenador do Programa de Pós-Graduação em Comunicação da Faac/Unesp. Pós-doutorado pela Open University, Reino Unido (Visiting Research Fellow, 2006-2007) e pela UFSCar (Universidade Federal de São Carlos), onde foi bolsista Prodoc/Capes (2008-2009) no Programa de Pós-Graduação em Ciência, Tecnologia e Sociedade (PPGCTS - UFSCar). Pesquisador visitante em University of Warwick, King's College London e Open University (Reino Unido).

\section{Kátia Viviane da Silva Vanzini}

Mestre e doutora em Comunicação pela Unesp (Universidade Estadual Paulista). Possui graduação em Comunicação Social: Jornalismo pela Universidade Estadual de Ponta Grossa, com especialização em Estratégias da Comunicação pela Universidade Tuiuti do Paraná. Foca seus estudos nas áreas de comunicação pública, novas tecnologias e políticas públicas de comunicação.

Pedro Luis Bueno Berti

Formado em Comunicação com Habilitação em Jornalismo pela Universidade Sagrado Coração

(USC), especialista em História, Cultura e Poder pela Universidade do Sagrado Coração (USC), especialista em Docência no Ensino Superior pelo Instituto Educacional Alfa. Mestre e doutorando em Comunicação pela Faculdade de Arquitetura, Artes e Comunicação da Unesp (Universidade Estadual Paulista). Membro do Grupo de Pesquisa Comunicação Midiática e Movimentos Sociais - ComMov

(Unesp/Bauru). 


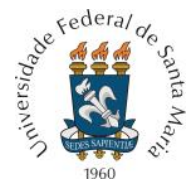

PROGRAMA DE PÓS-GRADUAÇÃO EM COMUNICAÇÃO DA UNIVERSIDADE FEDERAL DE SANTA MARIA

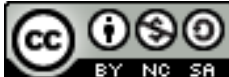

Esta obra está licenciado com uma Licença

Creative Commons Atribuição-NãoComercial-CompartilhaIgual 4.0 Internacional 